Ensino, Saúde e Ambiente-V10 (3), pp. 144-158, Dez. 2017

\title{
FEMINISMOS, IDENTIDADE E GENERO: CONVERSAS COM HARAWAY, BUTLER E ADICHIE
}

\section{FEMINISMS, IDENTITY AND GENDER: CONVERSATIONS WITH HARAWAY, BUTLER AND ADICHIE}

\author{
Ana Claudia Lima Monteiro ${ }^{1}$ \\ ${ }^{1}$ Universidade Federal Fluminense/Instituto de Psicologia/Departamento de psicologia/Programa de Pós- \\ Graduação em Psicologia, anaclmonteiro@gmail.come-mail
}

\section{RESUMO}

Neste texto será discutido, a partir da perspectiva feminista de Donna Haraway, a proposta de se pensar a constituição da objetividade e do conhecimento científico sob o viés da localização. Tal perspectiva desenvolve uma proposta bastante interessante para pensar a relação entre o pessoal e o político. A partir deste enfoque, fazendo proliferar narrativas não identitárias acerca do que é "ser mulher", pensamos o lugar do corpo. Posteriormente, traçamos um caminho para pensar a identidade de uma perspectiva não aprisionante, como "identidades fraturadas" nas quais não há nenhuma busca por totalização, mas, nos termos de Haraway, existe sempre proposta de coalisão. Neste ponto, o livro Problemas de Gênero de Judith Butler será trazido para pensar a relação que ela estabelece entre identidade, sexo e gênero. Por último, será retomada a relação entre as dimensões pessoal e política trazendo novamente a narrativa apresentada anteriormente sob o foco da distinção entre pertencimento e identidade proposta por Michel Serres.

Palavras-chave: Feminismos, Identidade, Gênero, Conhecimento Científico.

\begin{abstract}
In this text the proposal of thinking the construction of objectivity and scientific knowledge from the concept of localisation will be discussed from the feminist perspective of Donna Haraway. This perspective develops a very interesting proposal to think the relation between the personal and political approach. From this point of view we consider the role of the body, contributing for the proliferation of no identity narratives about what it means to "be a woman". Afterwards, we trace a way of thinking the identity from a non imprisoning perspective, such as "fractured identities" in which the is no search for totalization, but, in Haraway terms, there is always a proposal of coalition. From this perspective, Judith Bluter's Gender Trouble will be used to consider the relation that she establishes between identity, sex and gender. At last, the relation between the personal and political dimensions will be resumed, bringing the previously presented narrative up, under the perspective of the distinction between belonging and identity proposed by Michel Serres.
\end{abstract}

Key words: Feminisms, Identity, Gender, Scientific Knowledge. 


\section{INTRODUÇÃO}

(...) as pessoas estavam dizendo que meu livro era feminista. Seu conselho disse, balançando a cabeça com um ar consternado era que eu nunca, nunca me intitulasse feminista, já que as feministas são mulheres infelizes que não conseguem arranjar marido. Então decidi me definir como "feminista feliz". (ADICHIE, 2012, p. 09)

Neste trecho, anedótico e bem-humorado, Adichie inicia uma série brincalhona de relações entre "o que é ser feminista" e como ela se posiciona (ou não) nesta categoria. A partir disso, podemos acompanhar a série de idas e vindas em relação aos estereótipos feministas, aos engajamentos feministas, às autoras feministas e toda uma cadeia de sentidos e significações aprisionantes do que seria encaixar-se neste modelo. E porque a preocupação em encaixar-se ou não num modelo do que deveria ser feminista ocupa as páginas deste texto? Porque a palavra "feminista" nem sempre ocupa um lugar de prestígio, ou mesmo de aceitação nos lugares em que ela é proferida. Assim, o primeiro contato com esta palavra, narrado pela autora a seguir nos faz pensar:

Eu tinha catorze anos. Um dia, na casa dele, discutíamos metralhávamos opiniões imaturas sobre livros que havíamos lido. Não lembro exatamente o teor da conversa. Mas eu estava no meio de uma argumentação quando Okoloma olhou para mim e disse: "Sabe de uma coisa? Você é feminista!" Não era um elogio. Percebi pelo tom da voz dele era como se dissesse: "Você apoia o terrorismo!"' (ADICHIE, 2012, p. 08).

Ser feminista então pode significar um rótulo? E mais do que isso, um rótulo que não se deseja ter? Deste modo, trago à cena também um evento ocorrido na Universidade Federal Fluminense, em março de 2016, por conta das comemorações do Dia Internacional da Mulher. Fui convidada a falar do lugar de uma editora de revista científica $e$ mulher $n a$ Universidade.

A princípio, tive que me dar conta de que estes atributos estavam todos juntos, o que não era óbvio, mas, infelizmente tinha me passado desapercebido até então. Neste momento, o primeiro pensamento que me toma é: por que a surpresa? Por que ser mulher, ser editora, ser professora universitária não são coisas óbvias? Por que elas não podem seguir juntas? Por que ainda causa surpresa esta conjunção de coisa? Lembreime do livro Les faiseuses d'histoires no qual Isabelle Stengers e Vinciane Despret discutem a presença das mulheres na universidade - o que pode nos parecer banal, salta 
aos olhos quando percebemos que não foi "naturalmente" que adentramos este espaço. Vale acrescentar; nem nos mantemos com a mesma tranquilidade.

Porém, antes de seguirmos adiante com os questionamentos acerca de nosso pertencimento ou não pertencimento em determinados espaços, gostaria de sustentar o espanto que me tomou junto com o convite: afinal, com o mesmo espanto com que Adichie recebe o "rótulo" de "feminista", também me espanto com meu posicionamento. E, assim como as autoras citadas acima, não encontro nenhum descanso no fato de que sou: mulher, professora universitária e editora. Tais atributos me fazem "feminista"? De que modo?

Lembro-me então de minha trajetória antes da universidade, dos espaços que ocupei e como os jogos de pertencimentos e não pertencimentos constituíam meu corpo. Nesta apresentação, começo a construir uma narrativa a partir de outra mulher: minha mãe. Afinal, quais seriam as minhas primeiras referências do que se constituía como "ser mulher"? Em minha narrativa, as lembranças de uma mulher muito peculiar me saltam aos olhos: minha mãe nunca casou, ela vivia com meu pai, que era desquitado (na época - anos 60 - não havia divórcio ainda legalmente, o que havia era "desquite", o casal não moraria mais sob o mesmo teto, mas, não poderia casar-se novamente). Ela sempre trabalhou, mesmo contra a vontade do "marido". Sustentava a casa e, aproximadamente vinte anos depois, separou-se. Tais fatos, naquela época (ditadura civil-militar) no Brasil não eram coisas banais e faziam com que minha mãe fosse uma mulher bem peculiar para sua época. O mais interessante disto, é que, em toda minha infância, nunca ouvi falar sobre feminismo, teorias feministas ou algo do tipo. Assim como a proposta de Adichie, do seu jeito, a partir dos seus pertencimentos, com as suas próprias ferramentas, minha mãe era feminista. Sem o saber. Numa militância muito peculiar, muito localizada comportando todas as contradições que a vida cotidiana apresenta.

Narrar esta história, a primeira vista, pode parecer intimista, digna de habitar apenas uma biografia, ou mesmo diários particulares. Porém, contar esta história não é apenas apresentar uma parte pitoresca de uma vida privada. Esta narrativa tem a força política de trazer à tona uma série de alianças que constitui um corpo. E, neste sentido, o uso da palavra "corpo" não é banal. Este termo vem carregado de sentido, pois entendo que o corpo é este espaço de constituição do sujeito e do mundo, a interface, sempre porosa, entre o "eu" e o "mundo" (MONTEIRO, 2009). Evito aqui, deliberadamente, o 
uso da palavra "identidade". Tal palavra carrega em seu sentido armadilhas que tentarei problematizar ao longo deste texto. Portanto, para um início de conversa, aponto para dois caminhos que se seguirão adiante: a afirmação de que o "pessoal é político" e, posteriormente, uma discussão acerca do conceito de identidade.

\section{CONSTITUIÇÃO DE UM ESPAÇO POLÍTICO: PROLIFERANDO NARRATIVAS FEMINISTAS}

O trabalho realizado aqui segue a proposta metodológica indicada por Donna Haraway em seu texto Saberes Localizados, no qual a autora afirma a objetividade como forma de conhecimento localizado. Nas palavras da autora:

Assim, de modo não muito perverso, a objetividade revela-se como algo que diz respeito à corporificação específica e particular e não, definitivamente, como algo a respeito da falsa visão que promete transcendência de todos os limites e responsabilidades. A moral é simples: apenas a perspectiva parcial promete visão objetiva. (HARAWAY, 1995, p. 21)

Neste sentido, contar histórias não é simplesmente construir um diário pessoal. Mulheres como Chimamanda Adichie (2012), Svetlana Aleksiévitch (2016a; 2016b), Débora Diniz (2016), Bel hooks (2013) e Glória Anzaldua (2000; 2009), dentre outras, escreveram e narraram suas histórias e as histórias de outras pessoas para dar visibilidade ao que Eliane Brum chama de "desacontecimentos" (2014), para constituir um conhecimento que pulsa a partir destas histórias cheias de potência e vida. Traçar tais narrativas não é simplesmente a afirmação de um "eu", interiorizado e restrito aos espaços privados da vida cotidiana. Estas narrativas borram as divisões entre interior e exterior, entre público e privado. Traçam caminhos em que o agir e o fazer-se não estão separados, distintos. Esta proposta de uma política de escrita marca não apenas uma forma "alternativa" de produzir conhecimento, mas a proposta de compreender que todo conhecimento é marcado, localizado. A proposta de objetividade que nos move deixa entrever os atores constitutivos de toda prática científica. Não se trata apenas de afirmar que não há neutralidade, mas, de dar mais alguns passos: quais os critérios de minha escolha objetiva? Quais agenciamentos se tornam visíveis em minha prática de escrita? Qual o papel daqueles que eu interrogo em minha prática de pesquisa? Quais as relações de poder que se estabelecem nos dispositivos de pesquisa?

Longe de esgotar cada uma destas questões, torna-se necessário tornar cada vez mais presentes em minha narrativa pequenos efeitos que passariam despercebidos em 
contextos hegemônicos. Sobre o feminismo, como foi dito anteriormente, escolhi começar minhas palavras trazendo experiências que pouco contariam se meus esforços fossem para pensar tal categoria como um conceito filosófico que, aliás, ocupa um campo de disputas intenso. Ao invés de discutir conceitos, preferi trazer a história de minha mãe (uma, dentre muitas outras) não porque esta história se apresente como mera distração ou ilustração da "vida diária", ou, ao contrário, que seja emblemática do significado do que é "ser feminista". Nem uma coisa e nem outra. Trazer tal narrativa articula corpos e significados de uma maneira peculiar e ao mesmo tempo passível de coalisão, de sensibilizar outros corpos, trata-se de uma posição política: como se fazem práticas feministas no cotidiano, nos espaços em que as disputas de sentido pouco importam. Neste lugar, da vida cotidiana, os grandes conceitos se equivocam, se deslocam e se posicionam numa ação potente de construção de vidas. Neste sentido, o que fazer quando o que está em jogo não é um conceito, mas a própria possibilidade de existência?

O que emerge nestas narrativas é a potência que constitui a própria vida, como dissemos. "A objetividade feminista abre espaço para surpresas e ironias no coração de toda produção de conhecimento; não estamos no comando do mundo." (HARAWAY, 1995, p. 38) Apostar nas narrativas cotidianas nos conduz a uma proposta de pesquisa que, ao mesmo tempo consideram linguagem e corpo como práticas não ingênuas de constituição do mundo (Haraway, 1995) e reivindica uma maneira de compreender a identidade escapando ao seu sentido substancial (Butler, 2015). Sobre esta última, falarei melhor mais adiante. Me atenho aqui à questão da articulação entre linguagem e corpo e as consequências de tais considerações na constituição do que poderíamos denominar de um campo material-semiótico do que é "ser mulher".

Haraway nos convida a pensar a importância de se construir conhecimentos marcados em que haja, constantemente, tensões e efeitos vividos nas relações entre significados e corpos. Para isso, é importante a construção de formas de escrita que levem em consideração a fabricação dos mesmos. Mas não apenas isso, mesmo afirmando a construção do conhecimento, o que se busca não é a desconstrução, o esvaecimento dos sentidos, mas a possibilidade de afirmação de novos sentidos, sempre a se fazer, mas sempre efetivos. Não é possível falar da constituição de conhecimentos não marcados, isentos de localização e alianças, porém isso não significa dizer que nada importa, ou que qualquer coisa é possível - as duas faces da mesma moeda niilista mas, ao contrário, para afirmar a existência de possibilidades de vida não hegemônicas. 
Por isso, é importante compreender o campo de constituição do conhecimento como uma maneira de construir mundo, de fazer política.

Precisamos do poder das teorias críticas modernas sobre como significados e corpos são construídos, não para negar significados e corpos, mas para viver em significados e corpos que tenham a possibilidade de um futuro (HARAWAY, 1995, p. 16).

Ter a possibilidade de um futuro, o que podemos apreender desta expressão? Faço uma aposta no sentido de construir narrativas que façam proliferar mais e mais possibilidades de existências, aposto na multiplicidade. Neste caso, não importa somente falar de uma vida cotidiana, comum, mas, de apontar, naquilo que nas miudezas se difere, naquilo que borra as fronteiras e produz multiplicidade. O pessoal é político na medida em que traz à tona o que difere, sem a necessidade de universalização, mas com a potência do contágio. O que escapa à universalização é justamente isso: a possibilidade de "coalisão - a afinidade em vez da identidade" (Haraway, 2000, p. 53), de traçar conexões sempre parciais e fugidias. Haraway nos convoca a atuar nas fronteiras:

\footnotetext{
Fronteiras são desenhadas através de práticas de mapeamento; "objetos" não pré-existem enquanto tais. Objetos são projetos de fronteiras. Mas fronteiras oscilam desde dentro; fronteiras são muito enganosas. O que as fronteiras contêm provisoriamente permanece gerativo, produtor de significados e de corpos. Assentar (atentar para) fronteiras é uma prática muito arriscada. (HARAWAY, 1995, p. 41)
}

Portanto, o caminho para traçar o que Haraway denomina de um ator materialsemiótico implica em dizer que "o corpo é um "agente", não um recurso." (HARAWAY, 1995, p. 39) Neste sentido, quando falamos do corpo não nos remetemos ao corpo biológico, de fato, não faz mais sentido incorrer no erro de separar orgânico e produzido: "Quero traduzir as dimensões ideológicas "faticidade" e "orgânico" numa entidade desajeitada chamada "ator material-semiótico"” (HARAWAY, 1995, p. 40). Portanto, não cabe aqui falar sobre as determinações biológicas do corpo, ou mesmo, da separação entre corpo e subjetividade. As fronteiras entre interioridade e exterioridade, como dissemos, são móveis, traçáveis na medida das negociações que compõem o corpo. Não cabe, nesta proposta, reivindicar qualquer sentido para o fato de "ser mulher" como uma espécie de determinação biológica. Porém, aqui encontra-se uma armadilha: se não há determinação biológica, ou algo que se reivindicar, do que se constitui o então, como uma proposta feminista? Para responder a esta pergunta, retomo o que disse acima acerca da questão de pensar a identidade de maneira não substancial, 
como nos aponta Butler (2015) e traçar algumas considerações acerca de sua proposta, tendo como ponto de discussão o pensamento de Serres (2005) e Haraway (2000).

\title{
IDENTIDADE E GÊNERO: O QUE NOS RESTA SOBRE IDENTIDADE?
}

Gostaria de começar esta parte do texto traçando algumas considerações acerca do que Donna Haraway propõe, em seu Manifesto Ciborgue, como identidades fraturadas. Haraway afirma:

\footnotetext{
Não existe nada no fato de ser "mulher" que naturalmente una as mulheres. Não existe nem mesmo uma tal situação - "ser" mulher. Trata-se, ela própria, de uma categoria altamente complexa, construída por meio de discursos científicos sexuais e de outras práticas sociais questionáveis. (HARAWAY, 2000, p. 52)
}

Complementando esta linha de pensamento de Haraway, Butler propõe pensar o caminho seguido pelo o que Haraway denomina de "discursos científicos sexuais" e afirma:

\begin{abstract}
Em que medida é a "identidade" um ideal normativo, ao invés de uma característica descritiva da experiência? E como as práticas reguladoras que governam o gênero também as noções culturalmente inteligíveis de identidade? Em outras palavras, a "coerência" e a "continuidade" da "pessoa" não são características lógicas ou analíticas da condição de pessoa, mas, ao contrário, normas de inteligibilidade socialmente instituídas e mantidas. Em sendo a "identidade" assegurada por conceitos estabilizadores de sexo, gênero e sexualidade, a própria noção de "pessoa" se veria questionada pela emergência cultural daqueles seres cujo gênero é "incoerente" ou "descontínuo", os quais parecem ser pessoas, mas não se conformam às normas de gênero da inteligibilidade cultural pelas quais as pessoas são definidas. (BUTLER, 2015, p.43)
\end{abstract}

Nesta longa citação, podemos perceber a questão da identidade sendo colocada em termos de sexo, gênero e sexualidade.Assim como Haraway aponta, o problema se apresenta justamente nesta colagem entre identidade e qualquer atribuição estanque do que a mesma deveria ser.

Se em Haraway o problema se apresenta no fato de que a identidade pode confundir-se com este "ser mulher"; em Butler a questão se desloca para o que ela denomina de uma inteligibilidade cultural que organiza as pessoas segundo as normas de sexo, gênero e sexualidade. Linha seguida pelo pensamento foucaultiano, quando argumenta, na História da Sexualidade (1988), acerca da interdição da sexualidade e aponta para quatro diferentes operações de poder que, diferente de proibir a sexualidade, a coloca em mecanismos outros de relações de poder. Assim, quando Foucault fala na incorporação das perversões e da nova especificação dos indivíduos, ele nos diz:

O homossexual do século XIX torna-se uma personagem: um passado, uma história, uma infância, um caráter, uma forma de vida; também é morfologia, 
Desta forma, os mecanismos de saber e poder, como a medicina e a pedagogia, que atuam a partir do século XIX, fazem esta operação que liga identidade a tais mecanismos. O que há, portanto, é uma operação que liga sexualidade e identidade de maneira muito estreita. Esta proposta, aponta para um caminho no qual a relação entre identidade e sexualidade se fortaleça. Seguir tal caminho nos levaria a um ponto em que nos restariam dois sentidos a seguir: por um lado, poderíamos compreender tal leitura como um certo fatalismo - o que iria contra as propostas do autor de construir genealogias levando em consideração justamente os desvios e possibilidades de escape. Por outro lado, fazer a leitura desta proposta nos faz seguir um certo caminho já trilhado pelo autor. Esta proposta desembocaria numa simples repetição do que já foi dito, ou, o que é pior, a imposição desta mesma genealogia àquilo que escapa deste campo de relação entre sexualidade e identidade. Neste sentido, optamos por uma terceira via, pois, tomamos esta proposta como um problema e não como o ponto de partida de nossas considerações.

Existe a possibilidade de construir um sentido para o termo "identidade" que escape às armadilhas substancialistas? Podemos falar em identidade? Se não, como lidar com as singularidades que, ao emergirem, reivindicam um lugar na cena política? Se sim, como recolocar o problema da identidade em outros termos? Estamos aqui lidando com um problema delicado e com uma polêmica que se encontra no calor das discussões acerca dos posicionamentos políticos que tomamos e que são tomados todas as vezes em que as apropriações ameaçam tragar as diferenças. Em outras palavras, ao reivindicar o fato de "ser mulher", para criar um espaço em que haja a possiblidade de dizer "não" ao conhecimento produzido unicamente por homens, como devemos "nos identificar"? Somos "mulheres cientistas"? Como afirmar o conhecimento produzido a partir deste lugar? Percebe-se que a pergunta aqui já se desloca, pois, o que está em jogo não é exatamente o fato de se "nascer mulher", mas o fato de produzir um conhecimento que passa por outras vias que não aquela do conhecimento não marcado, generalizado, universal e, portanto, sem quaisquer marcas referentes, por exemplo, à cor, sexo, raça.

O problema, portanto, se apresenta a partir de uma variação: quem tem o "direito" de falar? De que lugar emerge esta fala? Há conhecimento científico que se produza neste lugar marcado? O uso da palavra "direito" não é banal e nem secundário, 
remete ao que Butler traça em seu livro como a questão representacional que se endereça ao que podemos resumir na seguinte questão: "quem fala em meu nome? Friso "em meu nome" justamente para problematizar a construção deste problema em termos representacionais, de maneira simples: quem me representa? Por que me representa? Com que direito me representa? Em outros termos, o conhecimento produzido "sobre mim" diz realmente respeito ao que "sou"? Adentramos aqui num problema interessante: a relação entre a representação política (em nosso texto expressa pelo problema: "quem somos nós?” E a representação científica, expressa pela questão da produção do conhecimento, seja sobre o mundo, seja sobre "mim". Para compreender a estreita relação entre estas duas questões lançaremos mão do conceito de porta-voz apresentando por Bruno Latour (Latour, 2000). Para este autor, não há diferença essencial entre representação política e representação na ciência. Trata-se sempre de constituir porta-vozes:

(...) o porta-voz literalmente fala em lugar de quem ou do que não pode ou não sabe falar (...). A força [do porta-voz] vem da palavra dos representantes quando eles não falam sozinhos nem por si, mas na presença daquilo que representam. (...) A solidez do que o representante diz é diretamente sustentada pela silente, porém eloquente presença do representado. (LATOUR, 2000, p. 120)

Tal conceito de porta-voz nos é útil aqui, uma vez que a ênfase é sempre posta no lugar desta presença que se supõe dos representados, seja na ciência, seja na política. Além disso, o representante, ao ocupar este lugar, fala em nome de um coletivo, apresenta suas propostas e, portanto, estabelece também suas regras. Daí a ênfase dada, anteriormente, ao direito da representação. O porta-voz ao mesmo tempo faz falar e calar aqueles que representa, uma vez que esta presença é sempre parcial, sempre passível de traição. A representação aponta sempre para um universal, para um ponto comum, enquanto que, no campo dos representados, o que há é a diversidade. Retomando o que nos disse Haraway, a busca de uma representação da "mulher" traça este caminho para a generalização: sabemos o que é ser mulher e por isso, somos representadas. Por outro lado, os representantes se multiplicam, se diversificam. A composição é sempre, necessariamente, parcial, temporária e efêmera.

Não há a possiblidade de uma representação fidedigna uma vez que o que ocorre é sempre tradução - portanto, as pautas de reivindicação também precisam ser, a cada instante, repensadas, rediscutidas, postas na mesa. O que se pensa ser um problema para um grupo de mulheres, não se apresenta da mesma maneira para outro. Como exemplo, Haraway traz a questão do trabalho, do direito ao trabalho, pauta das mulheres brancas 
estadunidenses. Ao se depararem com as mulheres negras, que sempre trabalharam, precisaram repensar duas posições. Precisaram compor outros acordos e entender que outras mulheres precisavam ter suas vozes ouvidas e suas propostas discutidas. Construíram os pontos de reivindicação sustentando o fato de que, em algum momento, haveria consenso, haveria coalisão, as propostas precisavam convergem. Esta convergência nunca se estabiliza, ela precisa ser constantemente feita e refeita a partir das diferenças que se apresentam na prática da representação. Neste sentido, a construção de um conhecimento que leve em conta tal proposta, deve ser, necessariamente, marcado, parcial, passível de ser, ao mesmo tempo, acatado e questionado, posto em dúvida. As conexões são sempre parciais e incompletas, mas, ao mesmo tempo, efetivas e efetuadoras porque fazem agir, geram ação e movimento. Porém, para além destas negociações parciais, cabe ainda falar em identidade? Cabe buscar uma representatividade que ultrapasse as fronteiras destas conexões parciais? E, mais importante, é possível construir representatividade sem identidade?

Sigamos nosso caminho, ralentando nossas perguntas, transformando tais questões, ainda bastante gerais, em problemas parciais, localizados, que nos façam seguir adiante, que não nos paralize. Retornemos à proposta de Haraway de pensar em termos de afinidade e não de identidade. No que ela nos ajuda? Ela nos ajuda a pensar os movimentos feministas como proliferação de vozes, de corpos, de fazeres e de saberes. Não se trata de buscar uma unidade que, em última instância, abarcará "todas as mulheres", projeto, de todo modo, colonialista, de apagamento das diferenças. Tratase de fazer tais vozes proliferarem, ganharem existência e contágio. Neste sentido, como a representatividade funciona no cotidiano de nossas vidas? Em meio às polêmicas separatistas, em que nos afileiramos em trincheiras representacionais, o que nos equivoca? As inconsistências, a própria multiplicidade que nos compõe. Num mundo onde gays e evangélicos são inimigos, existe a possibilidade de ser, ao mesmo tempo, as duas coisas (BELLO, 2016)? Mas como? Esta proposta se apresenta sem dor? Sem resistência? Sem corpo? Ao contrário. É justamente porque temos este corpo materialsemiótico, que é possível equivocar as fronteiras. Em nossos corpos cabem uma multiplicidade de experiências, de pertencimentos (SERRES, 2005) que não se confundem com aquilo que hoje chamamos de identidade - segundo Serres, o que vivemos é a confusão entre identidade e pertencimento, uma vez que, em última instância, a identidade não se confunde com nenhum de nossos pertencimentos, nem mesmo o nosso pertencimento sexual. 
Diga então qual é a sua identidade. A única resposta verdadeira: você mesmo, unicamente você. Isso se o princípio de identidade for enunciado da seguinte maneira: $P$ idêntico a $P$, termo que os lógicos e matemáticos têm o hábito de designar por três pequenas barras horizontais paralelas, para distingui-los do sinal de "igualdade" indicado por duas. (...) A confusão entre pertencimento e identidade começa por um grave erro de raciocínio que qualquer professor condenaria até mesmo no curso elementar. (SERRES, 2005, p. 99)

Seguir o caminho dos pertencimentos é apontar para o que constitui um corpo, na medida em que consideramos este corpo como aquilo que denominamos de ator material-semiótico, como dissemos acima. Pertencer não diz respeito apenas às relações externas, aos aparatos sociais e à composição das relações humanas. Pertencer significa ser constituído por todo um conjunto de práticas que marca os corpos de maneiras muito diversificadas. Não se trata de desconsiderar as marcas, mas de compreendê-las num campo de relações que faz com que algumas marcas sejam destacadas de outras. Historicamente tais marcas oscilam e se compõem de maneiras diversas. Apontar para as genealogias faz com que tais marcas ganhem relevo histórico, mas, ao mesmo tempo, apontam para outros caminhos que não aqueles já traçados. Assim, quando Foucault nos fala do surgimento do que ele denomina de sexualidade (1998), não é apenas apontando a genealogia de um olhar sobre a mesma, como dissemos acima, mas também, indicando outras formas de agir e de se fazer na composição deste campo. Não se trata apenas de indicar as formas de poder em jogo, mas também de marcar as diferenciações que compõem a sexualidade. Quais os pertencimentos que ganham relevo na história da sexualidade e quais são postos à margem da mesma? Além disso, como podemos escapar aos jogos de pertencimentos sem desconsiderar toda a rede de submissões e violências que se constitui com eles?

Neste jogo de composição dos pertencimentos, o erro não estaria em reconhecêlos, mas em torná-los a nossa única possibilidade de existência. Serres nomeia este erro de libido do pertencimento. Para ele, todos os preconceitos, todas as dissensões advém desta libido. Pertencer a um grupo, seja ele qual for, produz um campo de semelhanças atrativo que, dependendo da força com o qual atua, gera muitas violências e tende a apagar os traços divergentes. No curso de nossas vidas, na composição de nossos corpos e afetos, constituímos campos de pertencimento, compomos alianças que, ao mesmo tempo, produzimos e somos produzidos por elas. No caso específico que tratamos aqui, podemos falar, como Simone de Beauvoir, que vamos nos "tornando mulheres". Mas, tornar-se mulher não significa, necessariamente, compor o mesmo campo de afetos que possa ser identificado como homogêneo. Lembremos que, como foi dito acima, alguns 
campos material-semióticos exercem mais força do que outros, o que tende a excluir aqueles que não partilham do mesmo grupo de pertencimentos. $\mathrm{O}$ ponto chave para nossa discussão encontra-se na fato de que é possível falar da constituição de uma identidade que não se confunda com nenhum dos pertencimentos ao qual participamos.

Como dissemos acima, a possibilidade de se equivocar, de construir um corpo em que os pertencimentos são, a cada vez, mais e mais multiplicados, faz com que a construção da identidade não caia no erro do pertencimento. Neste sentido, a ampliação dos pertencimentos torna os corpos sensíveis, passíveis de ser afetados por um número cada vez maior de atores, humanos e não-humanos. Haraway, ao propor o ciborgue (2000), não estava apenas falando sobre as fronteiras borradas entre homem e máquina, estava também propondo pensar os agenciamentos coletivos que equivocam as fronteiras. Para ela,

\begin{abstract}
Nossos corpos são nossos eus; os corpos são mapas de poder e identidade. Os ciborgues não constituem exceção a isso. O corpo do ciborgue não é inocente; ele não nasceu num Paraíso, ele não busca uma identidade unitária, não produzindo, assim, dualismos antagônicos sem fim (ou até que o mundo tenha fim). Ele assume a ironia como natural. Um é muito pouco, dois é apenas uma possibilidade. O intenso prazer na habilidade - na habilidade da máquina - deixa de ser pecado para constituir um aspecto do processo de corporificação. A máquina não é uma coisa a ser animada, idolatrada e dominada. A máquina coincide conosco, com nossos processos; ela é um aspecto de nossa corporificação (HARAWAy, 2000, p. 106).
\end{abstract}

Os agenciamentos fazem proliferar estes corpos que não se submetem mais nem aos dualismos, nem mesmo ao processo de filiação no qual algo deriva de algo - como nos processos reprodutores. O corpo já não é a mais apenas o herdeiro biológico de seus antecessores, ele é também fabricado, pura negação de uma origem dada.

O que resta de identidade? Resta o traço, o caminho traçado, as alianças constitutivas. Não basta, portanto, negar os pertencimentos, mas deslocá-los, fazê-los errantes. Sob o olhar do corpo, das corporificações, orbitamos em diversos pertencimentos, sem, em momento nenhum, pousar definitivamente em nenhum deles. O que fazem então com a relação entre representatividade e identidade? Costurar afinidades, constituir campos de contato e contágio, fazer com que, nos centros de força dos pertencimentos, caibam a ironia, o equívoco. Além disso, afirmar que as representações são sempre parciais e localizadas. Como Arlequim, somo convidados a partir, a nos deslocar, e a construir nossos corpos dos retalhos do caminho, dos cheiros e gostos experimentados, das paisagens vividas. Trazer ao corpo a diversidade do mundo, tornar-se "maior". Porém, este caminho não é suficiente, como dissemos acima, 
vivemos num mundo em que os pertencimentos geram campos de força. Nesta última parte do texto, gostaria de falar um pouco mais sobre isso.

\section{IDENTIDADE E JOGOS DE FORÇA OU UMA VIDA FEITA NAS MIUDEZAS:}

Opto nesta parte do texto não a tecer "considerações finais", mas a seguir o caminho apontado por Haraway ao nos dizer que "Precisamos do poder das teorias críticas modernas sobre como significados e corpos são construídos, não para negar significados e corpos, mas para viver em significados e corpos que tenham a possibilidade de um futuro.” (Haraway, 1995, p. 16) Portanto, o caminho traçado acima seria menos um "manual de como devemos agir" e mais uma proposta provocativa, na qual o que importa é uma mudança de foco: ao invés de buscar normativas, buscamos focos disruptivos. Assim, gostaria de retomar a especificidade de minha história, contada na introdução deste texto: citar um fato tão corriqueiro e banal como a vida de minha mãe não é algo aleatório, é uma afirmação política. Trata-se de apontar para coisas bastante importantes sobre o fato de "ser mulher". Citar o trabalho, o sustento da casa, aponta para o equívoco dos papéis de homem e mulher, uma vez que quem “deveria trazer o sustenta da casa era o homem”, frase tantas vezes ouvida nos diversos espaços que habito. As relações de gênero, no Brasil, passam por esta ideia de "sustento da casa", a masculinidade, muitas vezes, é apresentada por este "poder" de "pagar as contas" da casa. Por outro lado, o que seria então esta mulher que "sustenta a casa?" Ela seria menos "feminina"? Como ocupar, ao mesmo tempo, o lugar de "provedora" e de "mãe"? Como equivocar estas relações e fazer desta heterogeneidade uma vida possível? Todas estas perguntas são política, apontam para um campo de relações e tensões que só podem ser construídos na vida diária, cotidiana.

Por outro lado, se constituir como mulher, no Brasil, passa também pelos relacionamentos afetivos. "Formar família" é algo que marca a vida da mulher desde seu nascimento. A indústria do casamento, das festas infantis, das cirurgias plásticas, da alimentação, da estética, dentre outras, são formas de pressão que circulam a vida das mulheres. Elas devem ser "femininas" e, portanto, devem casar e ter filhos, para isso, produzem conexões e redes variadas de pertencimentos que geram uma gama imensa de identificações ou de construções identitárias que perpassam suas vidas. Mesmo que muitas coisas tenham mudado ao longo dos anos, o fato de "ser casada" se apresenta como status social fundamental na vida das mulheres. Como exemplo, posso citar uma anedota: uma vez, ao assistir as aulas do doutorado, tive uma professora estrangeira que 
morava a muitos anos no Brasil. Ela é uma pessoa influente e extremamente inteligente e, no intervalo da aula, estava dizendo de sua dificuldade em entender o português mesmo depois de tantos anos aqui no Brasil. Achei, no mínimo engraçada esta colocação e prestei mais atenção em suas palavras que se seguiram. Ela dizia que a distinção entre "ser" e "estar" para ela era muito difícil, o que me provocou certa incredulidade, pois, achava extremamente "fácil" tal distinção. Pensava eu na regra geral: "ser" diz respeito ao que a pessoa efetivamente "é" - de maneira interessante, esta proposta está ligada também à identidade! - e "estar" diz respeito a algo que ela pode deixar de ser, é apenas um "estado de coisas". Enquanto eu estava pensando na regra geral, a professora apontava para o particular e nos dava um exemplo de quando ela foi numa festa e conhecer a esposa de um colega. Ao se referir a este fato ela diz: "Ah! Então é você que "está" casada com (cita o nome da pessoa)" Ao que prontamente recebe a resposta: "Eu não "estou” casada eu "sou" casada! Neste momento, me surpreendi com nossas próprias escolhas linguísticas. Como constituir um campo material-semiótico em que uma mulher "é" casada? Além disso, como nos espantar com esta maneira de nos constituirmos. E, por último, como viver num mundo em que sua mãe não se encontra neste pertencimento?

Trazer à cena o fato de que minha mãe não era casada com meu pai é também uma aposta política porque equivoca a relação entre mulher e casamento e entre casamento e maternidade. Em muitos momentos de minha vida passei pela estranha situação de ver minha mãe preenchendo formulários e colocando no campo "estado civil" a palavra "solteira", comigo, sua filha, ao seu lado. Como ser "mãe" e "solteira", mesmo vivendo com o pai dos filhos na mesma casa? As relações entre casamento, maternidade e papéis femininos e masculinos sempre foram muito peculiares em minha casa, o que não nos torna nem melhores nem piores, mas relações de pertencimentos possíveis, singulares. Não se trata de transformar as singularidades em regras gerais, mas de apontar para aquilo que, nas miudezas, transforma o geral em vidas vividas.

Para finalizar, escrever sobre a casa, as particularidades, a vida cotidiana não diminui o conhecimento, mas, ao contrário, afirma a potência das relações e dos equívocos, amplia os mundos e afirma as singularidades. Trata-se de mostrar a existência dos corpos em seus desvios e em suas potências, em suas possibilidades de futuro. Trata-se de equivocar os universais e de construir caminhos de conexão em que as histórias contam porque elas apontam para estas identidades fraturadas, para um campo em que cabem muitas "mulheres" possíveis, reais. Portanto, não se trata de 
abandonar a identidade, mas sim, de construí-la, de tecer histórias que digam respeito, ao mesmo tempo, daquilo que é singular, e daquilo que contagia. A identidade está menos no reconhecimento deste "ser" algo ou alguém, e mais nesta deriva de se construir a cada relação. Se usamos ainda a palavra identidade, não é para reificar um velho sentido, mas para dizer que não importa a palavra que usamos, mas o caminho que percorremos para fazê-la existir em nossas relações. Se esta palavra constrói relações de opressão, não a usemos, mas, se ela serve para construir conexões parciais, façamos seu uso. A palavra "identidade", deste modo, também se liberta de seu determinismo e constrói um campo material-semiótico para sua existência.

\section{REFERÊNCIAS}

ADICHIE, Chimamanda N. We Should All Be Feminists. New York: Anchor Books, 2014.

ALEKSIÉVITCH, Svetlana. Vozes de Tchernóbil: a história oral do desastre nuclear. Rio de Janeiro: Companhia das Letras, 2016a.

ALEKSIÉVITCH, Svetlana. A Guerra não tem rosto de mulher. Rio de Janeiro: Companhia das Letras, 2016b.

ANZALDÚA, Glória. Falando em Línguas: uma carta para as mulheres escritoras do terceiro mundo. In. Estudos Feministas, ano 08, 2 vol. 2000, p. 229-236.

ANZALDÚA, Glória. Como domar uma língua selvagem. Cadernos de Letras da UFF. Dossiê: Difusão da Língua Portuguesa n. 39, 2009, p. 297-390.

BELLO, Heder L. Tecendo o novo: peregrinações possíveis entre gênero, sexualidade e cristianismo. Monografia de Conclusão de Curso apresentada no curso de Psicologia da Universidade Federal Fluminense, 2016.

BUTLER, Judith P. Problemas de Gênero: feminismo e subversão da identidade. 8a. Edição. Rio de Janeiro: Civilização Brasileira, 2015.

DINIZ, Débora. Zica: do sertão nordestino à ameaça global. Rio de Janeiro: Civilização Brasileira, 2016.

FOUCAULT, Michel. História da Sexualidade: a vontade de saber. Rio de Janeiro: Edições Graal, 1988.

HARAWAY, Donna. Saberes Localizados: a questão da ciência para o feminismo e o privilégio da perspectiva parcial. Cadernos Pagu, vol. 5, 1995, pp. 07-41.

HARAWAY, Donna. Manifesto Ciborgue: ciência, tecnologia e feminismo-socialista no final do século XX. In. Antropologia do Ciborgue: as vertigens do pós-humano. Belo Horizonte: Autêntica, 2000, pp. 19-129.

HOOKS, Bell. Ensinando a transgredir: a educação como prática da liberdade. São Paulo: Martins Fontes, 2013.

LATOUR, Bruno. Ciência em Ação: como seguir cientistas e engenheiros sociedade afora. São Paulo: Unesp, 2000.

SERRES, Michel. O Incandescente. São Paulo: Bertrand Brasil, 2005. 